Mid-American Review of Sociology

Hausmann, C. Stewart

1979 "The Expanding Role of the Funeral Director As a Counselor: A Practical Approach," Mortuary Management 66 (June):48-49.

Mitford, Jessica

1963 The American Way of Death. New York: Simon and Schuster.

Oppenheim, A.N.

1966 Questionnaire Design and Attitude Measurement. New York: Basic Book.

Pine, Vanderlyn

1975 Caretakers of the Dead: The American Funeral Director. New York: Irvington Publishers, Inc.

Porter, Hale

1979 "Role Conflict," Mortuary Management 66 (October):13-14.

Raether, Howard and Robert Slater

1977 The Funeral Director and His Role as Counselor. Englewood Cliffs, New Jersey: Prientice-Hall, Inc.

Sudnow, David

1967 Passing On: The Social Organization of Dying. Englewood Cliffs, New Jersey: Prentice-Hall, Inc.

Turner, R.E. and Edgley, C.

1976 "Death as Theater: A Dramaturgical Analysis of the American Funeral," Social and Sociological Research 10 (July):377-392.

Vernon, Glenn M.

1970 Sociology of Death: An Analysis of Death-Related Behavior. New York: The Ronald Press Company.

Wolfelt, Alan D.

1979 "Grief-The Role of Today's Funeral Director," Mortuary Management 66 (September): $12-14$

1980 “'The Funeral Ritual': Expression vs. Repression," Mortuary Management 67 (May):11+

\section{NORMALIZATION OF A DEVIANT SUBCULTURE: IMPLICATIONS OF THE MOVEMENT TO RE-SOCIALIZE MILDLY RETARDED PEOPLE ${ }^{1}$}

Cindy Rhoades

University of Oregon

Philip Browning

University of Oregon

In the 1950s and 1960s a growing school of politicians, social scientists, and high-level professionals in correctional, health, and social services began a serious enterprise to elucidate the disasterous effects of institutionalizing juvenile delinquents, criminals, mentally ill and mentally retarded people. A famous example of this critique is Goffman's 1961 book titled Asylums, which points out that the institution, rather than a patient's illness, is the most important factor in forming a mental patient. The "total institution" was discovered to be dehumanizing, brutalizing, and contributive to the acquisition and maintenance of deviant attitudes and behaviors.

Institutionalization also became an economic disaster. It became difficult to justify costly institutional versus community modes of control with many deviant populations deemed eligible for support by welfare programs. As the United States wrestled with fiscal pressures in the 1960s, deinstitutionalization and community treatment alternatives soared in popularity to be accepted as the most sophisticated social control practice (Scull, 1977). By the 1970s, the contemporary movement to reintegrate the mad, bad, and incompetent into society was well along its way.

Rehabilitating deviants within the community has been especially prominent with the mentally retarded population. This is due in part to the societal recognition of retarded people as first-class citizens with an ascribed rather than motivated deviance. Furthermore, due to the cognitive/behavioral limitations associated with mental retardation, this population requires 
specialized guidance and training in basic survival skills in order to live independently within the community.

The traditional professional approach to this community integration movement has been based on the normalization ideology, which has played an extremely important role in shaping the therapeutic programs designed for mentally retarded people. Normalization was originated in Sweden in 1969 by Nirje, then Executive Director of the Swedish Association for Retarded Children. He conceptualized it as:

Making available to the mentally retarded patterns and conditions of everyday life which are as close as possible to the norms of society (Wolfensberger, 1972:181).

Emphasis for change in this definition is upon the problematic aspects of Scandinavian society, and is consistent with the progressive approach taken by correctional/rehabilitative agencies which are found there.

The concept was reformulated by Wolfensberger in 1972 for implementation in American society. For the purposes of comparison, his definition is:

Utilization of means which are as culturally normative as possible in order to establish and/or maintain personal behaviors and characteristics which are as culturally normative as possible (p. 28).

Here the emphasis is switched to the behavior of the individual, the goals becoming the adjustment and maintenance of behaviors and characteristics which are as "normal" or typical as possible. With an emphasis on changing the individual's behavior to conform to society expectations, this reformulation of normalization is consistent with American correctional/rehabilitation philosophy and practice.

A major goal of normalization is to resocialize these persons by teaching them to shed their retarded identity and assume new behaviors which are defined as normative. The experience of being normalized is intended to involve a dramatic personal change for the retarded person, whereby he or she takes on new identity. The resident ostensibly enters the community residential facility (or group home) to learn to shed his or her "retarded" identity and assume the new role of an independent adult living within the community. From the time of entry into the program, he or she is involved in a comprehensive socialization process which is assumed to entail a dramatic re-orientation.

Learning to shed a retarded identity can be usefully conceptualized in terms of subjective phases which residents experience in the course of moving through the group home program. Traditionally, studies in the sociology of deviance which focus on socialization have been concerned with the process of becoming deviant (e.g., Becker, 1963; Matza, 1969; Scott, 1969). They have examined phases which the individual passes through as he or she assumes a deviant identity and career. This research examined the obverse of this process, i.e., learning to leave the deviant identity and assume a more normal one. Specifically, it was an examination of the experiences that mildly retarded adults face in learning to live within their community as normal adults do. After a brief introduction to the methodology employed, an elaborated discussion of the daily lives of retarded people being normalized is presented in two sections. The first results section introduces an analytic framework which highlights the process of becoming invisible within society. The second results section, which is derived from the analytic framework, presents several contradictory consequences of the normalization strategy.

\section{METHODOLOGY AND RESEARCH SITE}

This study was conducted in a group home for mildly to moderately mentally retarded adult in a middle-sized city in the United States. The research setting was "ideal typical" of the current implementation of the normalization principle, since service providers in the group home had a basic understanding and belief in the general thrust of normalization and were at tempting to apply it in their programming. Eighteen retarded consumers of the services were receiving training which included 
daily work responsibilities and freedom to explore their community. Thus, the focus of the research was upon their experiences in three settings, i.e., the work setting, the community, and the group home.

The general design of the program was intended to provide a halfway experience between the parental home or institution and the complete freedom of apartment living. The end goal for the retarded person was to live in his or her community in a manner which was as independent as possible. The experience provided by the group home in this location was therefore consistent with the major corollaries of normalization.

Four mildly mentally retarded adults were selected as key subjects for the study. Subject selection was made in collaboration with a service provider in the group home after six months of preliminary investigation. The sample consisted of two women and two men whose intelligence status was labeled educable mentally retarded (EMR). Three were graduates of special education programs and one was previously institutionalized. These consumers of normalization determined who else was observed in the study. That is, the persons with whom consumers came into direct contact and interaction in the research settings were informants of normalization by reference to their associations with the retarded consumers. Informants included service providers at the group home, various staff at the work setting, and citizens in the community.

The research was conducted at two levels-descriptive and analytic. At the descriptive level, participant-observation and unstructured interviewing techniques were used to systematically gather data for the purpose of describing the process of normalization. Observations and interviews in the research setting were made over a two-year period at various times during the hours between 6:00 a.m. and midnight. Detailed field notes were recorded after each observation session.

The grounded theory method of analysis was used at the analytic level to develop an explanation of the factors underlying the observed process of normalization (Glaser and Strauss, 1967). Specifically, the overall process of normalization was discovered to be a practice whereby attempts were made to transform a category of people from a "visible" to an "invisible" social status. This finding has provided the foundation for a whole new way of conceptualizing the experience faced by mildly retarded adults learning to live independently in their community.

\section{THE PROCESS OF BECOMING INVISIBLE WITHIN SOCIETY}

The need for people to "blend" and "fit" in to this society is embedded in standard interactional patterns. Cultural diversity among groups is tolerated only within the limits of the normative social structure. The consequences for people who deviate from normative standards are varied and may range from a frown to institutional confinement. Somewhere within that range is the contemporary ideology and practice of normalization which addresses a deviant and highly stigmatized category of people, i.e., the mentally retarded.

Normalization is adopted by group home facilities as a guide for teaching retarded adults necessary skills for assimilating into the community. When the retarded person first enters the group home, inappropriate behaviors stand out making him or her undesirably visible to the general community. Following is a list of behaviors which the group home program strives to modify, but any behavior that would indicate retardation to the staff would be included: inappropriate appearance (e.g., dress, obesity, facial expressions, walk, speech, grooming); poor eating habits and bad manners; poor cooking and shopping skills; inadequate skills for managing money; inadequate skills to use public transportation; inability to make and keep appointments (e.g., doctor, social); poor work habits (e.g., slow on the job, high absentee rate); and inappropriate sex behavior. The idea is to extinguish these behaviors so that the retardation will be invisible to others, or go unnoticed. Ideally, the retarded person goes from the point of visibility to invisibility thereby learning to blend. Put another way, this research has led to the finding that normalization practice is basically involved in selecting out a highly undesirable visible category of people and systematically attempting to camouflage 
them. The group home is the vehicle of this movement whose business is "the creation of invisible people."

What follows is an examination of the meaning that this transformation process has for retarded people. This discussion centers around the experiences faced by residents being normalized, the settings in which the normalization process occurred, and the normalization agents.

\section{NORMALIZATION AGENTS}

In spite of the popular acceptance of normalization as a mode of operation, certain conditions make it susceptible to a lack of uniformity in its implementation. First, as with any value laden theory, various interpretations are made by even its most avid proponents as to what constitutes appropriate goals and methods. Second, various levels of commitment are made to normalization, ranging from daily absorption with the task of accomplishing its goals to only infrequent reference to its principles. Finally, there is considerable variation in the levels of awareness and understanding among the many normalization agents as to its existence and significance. This lack of uniformity has serious implications for retarded individuals who are being normalized.

Group home staffs are the primary normalization agents. It is their understanding, interpretation, and practice of the ideology which determines the direction of the program plans developed for the retarded residents. Furthermore, of all the normalization agents, they are generally the most committed to its implementation. For example, group home staff in this study make the statement in their handbook: "We believe in the principle of normalization."

The group home strategy also calls for the involvement of secondary normalization agents. These include work staff members, family, friends, acquaintances of, and even strangers to the retarded person. These persons act as various kinds of agents in the sense that each produces some type of effect on the retarded person being normalized in the course of daily interaction. Each has some impact on the retarded person's ability to succeed in his or her training and to develop capabilities for coping with problems which arise in the outside "intelligent" world. Thus, the overall process of normalization extends beyond the group home setting work and other life experiences of the retarded person, where an agent's understanding of normalization is often superficial and frequently non-existent.

Retarded individuals being prepared for community integration are generally under the supervision of more than one staff person in more than one setting, e.g., group home and sheltered work facility. When this occurs, differences in such conditions as organizational goals, and staff training frequently hinder a cooperative commitment to and common understanding of normalization between settings. For example, group home staff may define residents as adults and tell them to behave accordingly, while work supervisors are simultaneously defining residents as "kids" and judging their abilities in accordance with that definition. In this study which included two sheltered employment settings, the majority of the work staff who directly supervised retarded employees were not even aware of normalization. Yet these retarded persons were fully engaged in a normalization program in their group home.

Another condition which affects a lack of consistency in normalization practice is the limited exposure that the general public has to retarded persons which, in part, explains the failure of the former to comply with principles of normalization in interactions with the latter. Except for limited news coverage and public service announcements, occasional documentary television specials on the handicapped, and the popular culture interpretations of being mentally retarded in society as recently portrayed in television movies and series, the media has done little to educate the public on the community integration of the retarded. Although American society is beginning to integrate mentally retarded people, its normal members remain uneducated about normalization and continue to hold many stereotypical notions about the disability.

In summary, the different agents who have contact with the retarded person being normalized are seldom coordinated 
in their understandings and agreements of what constitutes appropriate goals and methods of accomplishing normalization. The outcome of these differences can be a myriad of contradictions which bring to bear important and frequently disturbing consequences to the retarded person. Such instances are forthcoming in the second results section of this paper.

\section{Group Home Setting}

Tinsley, O'Connor, and Halpern (1973) describe group homes or community residential facilities as:

Any community based residential facility which operates 24 hours a day to provide services to a small group of mentally retarded... persons who are presently or potentially capable of functioning in the community with some degree of independence (p. 4).

Residents in a group home setting are there to receive habilitative services that will assist in the development of independent living skills necessary for survival in the community. The general design is said to provide halfway experience between the parental homes (or institution) and the complete freedom of apartment living. Under this type of program, retarded persons are finally able to live in an environment which, in principle, will spare them the stigma and estrangement characteristic of large institutional facilities.

Residents who first entered the group home during the course of this research came with the belief that they would learn to live independently in the community, though they were typically unable to designate or speculate when that time would come. Donald's response was typical of the residents interviewed:

I want to get my own apartment... to be able to live on my own by myself... I think I can do it too (excerpt from field notes).

When asked why they decided to enter the group home program, residents indicated that either a vocational rehabilitation counselor or a family member encouraged them to do so. Two retarded informants related their (or a family member's) age to their decision to enter the program. As one 29 year old woman put it:

Well, I'm old enough to be on my own now, Cindy, and that's all there is to it. And so I left my sister's house ... to come here and learn a few things (excerpt from field notes).

Another resident, a 26 year old woman, expressed concern for her mother's situation:

See my mom lives by herself now since my dad died and she's gettin' pretty old. I wanna get married when the time is right... I wanna learn how to shop and cook and keep my budget and things like that. I'm in the independent kitchen now (excerpt from field notes).

Residents reflected an optimism regarding the achievement of their future independent status in the early part of their participation in the group home. Residents who entered the home made a commitment to be normalized and in doing so resolved to work toward becoming independent. The experience was novel and they articulated the belief that they would complete the program. It was only a matter of time, however, until they lost this belief and resigned their goal of future independence for an attitude of permanent acceptance of group home life. Only one resident graduated from the group home to a satellite apartment in the course of this research. ${ }^{2}$

The group home "exit program," i.e., the phase of the normalization program where residents learned what staff defined as "critical housing and budgeting skills," seemed to be a pivotal point where residents resigned their "pre-resident" goal for independent living. The exit program revolved around the independent kitchen where individual residents must shop for themselves, prepare all meals, and maintain the kitchen. It represented the final behavioral test before independent living. The program coordinator explained: 
It is here that the cooking skills, housekeeping skills and budgeting skills are truly probed. Up to now, the resident did not have to purchase food and had to cook only one evening meal a week. Once in the independent kitchen, the resident is monitored on a diminishing basis until it is shown that he or she can indeed function independently in this area. When a resident is able to purchase food, prepare meals, maintain the kitchen, pay rent and live within a budget, he or she is ready to move into independent housing (excerpt from field notes).

Most residents in the course of this research, however, did not proceed to this exit phase, and those who did remained there or were cycled back to the group cooking program. At best, the independent kitchen represented an in-house status symbol of independence for participating residents. Experience with the independent kitchen helped to solidify an attitude of permanent acceptance of group home life as residents came to recognize that entry into the exit program did not lead to apartment living. At the exit program stage, independent living came to mean life in the group home, with residents and staff members who represented constancy and a built-in, settle-in surrogate family.

Planned, family-type, group home activities also served to encourage the settling-in process. For example, activities were regularly scheduled for holidays and special events. The entire group home population got involved in planning birthday parties for each resident. At a resident weekly house meeting, details were planned for Cheri's twenty-seventh birthday as reported in the field notes:

This Saturday is Cheri's birthday, I learned, and staff member asks her if she has decided what she wants for the meal. Cheri answers, 'Yes, I have. I want chicken and two kinds of salad with green salad and fruit salad, and watermelon.' Staff member says, 'That sounds like a picnic to me. Shall we plan to eat outside?' Everyone responded enthusiastically with 'yeh's' and applause (excerpt from field notes).

Residents further learned to comfortably identify with each other as a group through forming teams to participate in special sports activities. For example, the group home staff seasonally organized softball and volleyball teams to compete in "special tournaments" involving other mentally retarded participants from sheltered workshops in the area. Participation in these competitive games served to further strengthen the cohesiveness of the residents as a group, and facilitated a feeling of permanently settling in.

In summary, residents did not have an established frame of reference as to what constituted successful completion of the program. As they continually failed to see their. peers graduate from the program, the "pre-resident" hopefulness for independent living was suffocated. Gradually at first, new residents began to "settle-in." That is, within a year, they began to identify with the group home as their home, developing a sense of belonging and permanence to the place and losing sight of the goal to leave it.

\section{Residents}

Residents must show commitment to their normalizing experience by adopting a view of normalization that is consistent with the staff's interpretations. If they do not, their choice is to reform or leave. The tactic of temporary suspension is designed to give residents the opportunity to reflect on their participation in the group home and then make an independent decision. It also has the less apparent result of serving as a strategy for persuading residents to absorb the ideology of normalization as defined and implemented by staff.

When a resident deviated from set standards in the group home, indicating a lack of commitment, the normalization process was interrupted and his or her training risked coming to a complete halt. There was some room for deviation before the process was officially interrupted and made public to other residents, but the limits could only be stretched so far. The extreme consequence of failing to indicate a commitment to the program through compliance to program regulations, was temporary suspension from the group home, and in some cases, involved a return to the institution for a limited stay. A less severe consequence was a short-term stay with family. In both situations, the resident was expecte to re-evaluate his or her role in and 


\section{Mid-American Review of Sociology}

commitment to the program and make a decision as to whether or not he or she wished to return.

A resident, in one situation, was failing to comply with the hygiene requirements of the program. He continually failed to shower and wear clean clothing. A staff member explained:

Well, he's basically not complying with requirements of the program and so he is going up to State-school to make a decision. He says he never decided to come here in the first placethat they placed him-which is true- and now he is saying that he doesn't have to do things he doesn't want to do. He has no problem with doing things he wants to do, like the driver's training, but he won't do things like change his underwear and take a shower. I don't think he is making progress. I think he might see what State-school is and then decide to come back here after two or three weeks (excerpt from field notes).

These strategies of developing an understanding of and maintaining a commitment to the goal of normalization involved important consequences for staff and residents. First, staff had to convince residents to accept at face value the judgment and direction that they provided. Furthermore, staff had to indoctrinate residents into believing and accepting that residents were individually responsible for their success or failure in the normalization program. In essence residents had to relinquish control for determining the appropriateness of their actions to staff, while simultaneously assuming responsibility for their inappropriate behavior and/or failure to change behavior defined as undesirable.

The explanation as to why residents were easily instilled with the belief that they were individually responsible for their success or failure was rooted in behavior management, the technological approach used to implement normalization. The center of this approach is to define an individual's behavior as the problem, and then take steps to change it. Rather than recognizing the contributing effect of the person's significant others and general milieux, behavioristic approaches focus on the individual alone. In the determination of success or failure for residents
Mildly Retarded People

in this study, the individual behavior was seen in isolation from influencing social situations. Consequently, when a person failed, she or he took the burden or responsibility regardless of the variety of conditions which were significantly contributing to the failure. Common reasons for resident failure, as indicated by staff, were "failure to cooperate" and "lack of motivation;" no mention was made of environmental factors.

Maintaining commitment among the residents in this study was not limited to enforcement strategies adopted by group home staff. The residents often reminded each other of the necessary commitment to normalization by telling each other to "act like adults," and by criticizing one another for acting like children. It was not uncommon to see particular residents point out behavior which was defined as inappropriate by staff, or to warn one another against acting childish. At a weekly resident meeting one resident remarked to the group:

(serious tone of voice) Now I don't know how many of you know it, but Joe is moving in here this weekend. Us guys are gonna have to show Joe we're adults and not little babies. And I mean it! (excerpt from field notes).

In addition to enforcement tactics, another conflict related to making a commitment involved the new resident entering the group home. Although the label of mental retardation was something many new residents despised and had learned to deny and avoid, they had to accept and admit the label to enter the group home program. By joining the program, the resident faced the contradiction of admitting his or her undesirable visibility in order to become desirable invisible. Put another way, he or she had to admit to being retarded in order to learn how to be normal.

Still another conflict which faced residents in this study was the absence of a consistent and positive reference group which supported an emergent image of themselves as independent adults. As with any major re-socialization process, those undergoing an identity change often subjectively experience a conflict between their current identities and the image of what they are to become. The current image must be effectively de-emphasized in light of 
the new one if the process is to succeed. In other words, the new emergent self must have reference in a new and complementary social group.

Since residents find their frame of reference from group home and work staff who are inconsistent in their values and expectations, they are deprived of a reference group which provides a perspective from which they can estimate their conduct and corresponding identity. Thus, residents learn to alter their level of competence in a manner in which they are addressed by others who interact with them. For example, residents will take no initiative or responsibility on their own when they are working, if the supervisors simply give them orders and don't expect them to exercise any judgment. Joe was seen performing the same tasks-both poorly and competently in different instances depending, it seemed, on how he was supervised at the task and the amount of responsibility he was given. When he was required to make judgments and decisions while he worked, he was responsible and effective in his job. When someone was telling him every move to make, he tended to stand around and wait to be told when, where, and how to make every move.

The conflicting effects of an inconsistent reference group were further complicated for residents through differing group home and work staff evaluations of a resident's level of competence and independence. For example, while Molly was defined as competent and was given more responsibility than Donald at work, the opposite was true at the group home. At the group home, Donald was in the independent kitchen-a symbol of success and growth toward independence. Molly, on the other hand, was still cooking in the group cooking program under close supervision-deemed less competent than Donald at this activity. Both residents were faced with the task of simultaneously maintaining different levels of competence depending upon the direction given by different staff. Lack of a consistent reference group in this situation placed the residents in contradictory situations where their retarded and non-retarded identities were simultaneously emphasized.

Related to the lack of a consistent reference group is another dilemma, i.e., the absence of specific role models that will provide a positive behavioral image of what the residents might become. Retarded persons' models include all the people they come into contact with who already blend, who are socially defined as normal, which is an extremely wide range of people. In the process of interacting with this wide range of normals, the residents are confronted with a variety of reactions to their retarded behavior, most of which serve to validate their retarded role. This is particularly apparent in the public sector where people hold stereotyped notions about mental retardation.

Group home staff in this study attempted to structure modeling within the program by acting as role models themselves. But this seemed to be unsuccessful because of the nature of staff/resident relationships. Residents experienced staff as authority figures, which made it difficult to view them as reflections of behavioral goals.

Residents themselves comprised the primary reference group for providing role models. This meant that retarded persons who were in the process of assuming a new identity were constantly relating to persons who reflected their undesirable role. Resident's daily activities, for the most part, involved interactions with other retarded persons at the group home and at work. The effect of this situation was to impede the retarded person's assumption of a more normal identity, since the retarded reference group was limited in how it could promote a projected identity of normalcy. The immediate outcome was a conflict hindering the behavioral change of the retarded person within the social processes engineered to transform him or her. A basic dilemma seemed to arise; retarded persons ended up serving as one another's role models for identity transformation.

The following results section further elaborates upon the conflicts facing the retarded resident learning to blend into society. Specifically, several contradictory consequences of the normalization strategy are presented.

\section{CONTRADICTORY CONSEQUENCES OF NORMALIZATION}

A pervasive consequence of putting normalization into practice is that it tends to contradict its principles-despite the 
good intentions and careful programming provided for retarded residents by group home staff. This research discovered several contradictory consequences of attempting to make retarded people invisible, which recurred empirically during interactions between residents and normalization agents in the group home, work setting, and community. For the purpose of explication, these basic social processes have been labeled "super-standards of conformity," "over-programming," "impression management and propping," and "the sympathetic agent and contingency norms."

\section{Super-Standards of Conformity}

This contradictory consequence refers to the imposition of "super-standards of conformity" upon residents which are deemed necessary for promotion in the group home. That is, some behaviors which require testing in the process of normalization are considered, at most, petty norm violations when committed by normal people. In this study the observer was asked to assist in "counting appropriate eating behaviors" at meal time.

I was asked to observe Keith's eating behaviors during dinner. I was supposed to count appropriate and inappropriate eating behaviors and mark them down on a report on Keith's eating habits. Jim (staff) told me it was a behavior Keith needed to work on. 'How do I judge what is good and what is bad eating behavior,' I asked, wanting to be fair in my judgment. Jim replied, 'Judge Keith as you would expect any person to eat if you were out to dinner with them; count for eating with fingers, mouth open, belching, loud talking, things like that' (excerpt from field notes).

In this situation, the resident's poor rating in the test for appropriate eating behavior served to detain his status in the lower stratum of the normalization process. A dilemma arose: In order to be promoted in the normalization process, the retarded person was required sometimes to be tested for behavior which is not necessarily required of normal adults.
In another instance, a service provider demonstrated the irony involved in the process of imposing super-standards in an interview.

Staff: Jerri is a 'moneyholic.'

Observer: A moneyholic?

Staff: 'Yes. She has no ability to budget her money. When she ran out of the money from her paycheck, she went to the bank and told them she had lost her bankbook and managed to withdraw $\$ 25.00$. I am holding her bankbook so she can't withdraw money-and she does it anyway. That's her biggest problem-she can't budget her money' (excerpt from field notes).

The retarded resident in this event received a new label, "moneyholic," for a behavior in which many normal people have engaged. Though the act of obtaining the money took some ingenuity on her part, the resident's behavior was interpreted as negative and "non-normalizing" and served to enhance her label of incompetence. An irony is suggested: Even though a resident's actions may outwardly demonstrate normalcy, they may be interpreted and defined as inappropriate. In the thrust to normalize, staff may set up criteria for evaluations which are over and above normative expectations for normal people, leading to the consequence of imposing super-standards of conformity.

Another example of super-standards is the "diet table program." The group home coordinator explained that this strategy was the result of an effort to eliminate obesity, an attribute considered deviant by the principles of normalization:

Obesity is something we will no longer tolerate around here. The diet tables have no bread or starchy things, and each person who participates in this program is required to weigh every week and have their weight charted. Their progress is announced at resident meetings (excerpt from field notes). 
Although obesity is culturally undesirable in this society, and many people seek expensive professional and/or medical advise from "weight control specialists," it is not socially abnormal or deviant to be overweight. The decision to lose or gain weight is private in this society, unless we elect an occupation which requires a specified level of physical fitness, e.g., dancer, fire fighter, gymnast. As with the test for appropriate eating behavior, mandatory diet tables for overweight residents represent the imposition of super-standards of conformity upon retarded residents in the sense that they transcend social rules placed upon normal and sometimes overweight adults.

A more simple demonstration of imposing super-standards was reflected in the following comment from a group home staff member to a resident who was drinking a soft drink:

'Molly, your (soda) pop in the glass looks real good. I mean it's better than chug-a-luggin' a bottle. It looks real nice the way you got a glass and put some ice in it and put your pop in the glass to drink it.' Molly squirms in her chair and smiles (excerpt from field notes).

Drinking soft drinks from a glass with ice is considered appropriate behavior in this culture, but then so is drinking from a pop bottle-certainly within one's home. The simplicity of this scenario indicates the extent to which residents' behavior is sometimes measured against expectations which exceed socially acceptable standards. Super-standards of conformity experienced by residents in this and the above situations seemed unnecessary and potentially confusing to retarded residents attempting to make sense of a normal world.

Beyond generating immediate confusion, the imposition of super-standards also generates more dramatic consequences such as suspension. For example, the resident mentioned earlier who was failing to shower and wear clean clothing was temporarily suspended from the program to affirm his commitment. Although cleanliness is highly valued in this society, as is indicated by the extensive type and variety of hygiene products available on the market, some normal people elect to shower infrequently and wear soiled clothing. The consequence of such a choice may be the loss of friends and acquaintances or more likely reprimand, but not institutionalization. Again, the resident who faced this consequence was meeting criteria for evaluation which exceeds normative expectations placed on non-retarded people.

\section{Over-Programming}

"Over-programming" refers to the intensity of behavioral programming that is prescribed for residents by staff. In this study, virtually every waking hour of the residents' lives was programmed to direct behavioral change in the way they dressed, talked, ate, worked, managed money, cleaned house, groomed themselves, cooked food, related to the opposite sex, acted in public, etc., etc. Even leisure time was programmed into time slots which were not reserved for specific tutoring activities. For these residents, group home life meant a consistent reminder through a constant entourage of behavioral programs that they must improve who and what they are.

In the following interaction, over-programming was brought to the observer's attention when she attempted to schedule an interview with the resident:

I say 'Molly, I was wondering if we could get together tomorrow for awhile to talk.' 'Sure, Cindy, sure,' she replies. 'Well, what time do you get off work tomorrow-don't you come home early on Wednesdays?' I ask. 'Yes, I do, Cindy-I do get off early,' Molly says. 'Well, how about if we meet at about $3: 30$ ?' I ask. 'I have to go to the bank tomorrow,' she says. 'We should still have time,' I say. 'I also have to cook tomorrow,' she says. 'And the next day I have my laundry and dishes, so I don't know when for now. You could talk to Lucy (program coordinator) because I think the resident meeting is tomorrow too' (excerpt from field notes).

A conversation with another resident, Kevin, illustrates a more frustrated feeling toward "over-programming:" 
'I'm a hard workin' man,' he says. 'I work out on the dock unloadin' stuff and it's hot! I work hard! I want some time for myself cause I'm sick and tired of it!' (His tone of voice is angry. I've never seen Kevin show this kind of anger in the year I have known him.) (excerpt from field notes).

Kevin's show of frustration toward not having enough time for himself was unusual in the group home. Molly's reaction was more typical-she seemed to feel the restriction of her time, but accepted it as part of the requirement of group home life. In keeping with the necessity to maintain commitment to group home standards, residents occasionally griped but they still complied with programming requirements.

\section{Impression Management and Propping}

Group home residents traveled freely within the community, walking to their neighborhood market, taking buses to the downtown area, their jobs, and leisure time activities. Movement within the community put these retarded persons in the "public eye" where mentally retarded people have a stigmatized social identity. Having committed themselves to the goal to become normalized adults, residents were confronted with the important interactional consequence of how to manage their stigma in such a way as to create the impression of being normal.

In the course of interacting in public life, then, the residents had to learn the ability to "put on" and reflect the proper impression for the social situations they found themselves in. This meant they had to develop special techniques for passing themselves off as normal. As Edgerton (1967) found, this study confirmed the necessity of passing as a coping mechanism to deflect a retarded identity. Indeed, the ability to "pass" was taught within the group home program in the course of modifying and extinguishing undesirably visible behaviors. Through this process residents learned the technique of impression management whereby they concealed their retardation and reflected a behavioral image of normalcy.
In the course of transforming their retardation from socially visible to invisible, a number of props were adopted by residents and conferred upon them by staff. These served to assist in developing impression management abilities, thereby facilitating the resident's ability to blend into the community. Props are possessions that indicate a normal status by virtue of their attachment to the resident. In this sense, they can be thought of as a material aspect of "passing," i.e., a tangible object used to indicate normalcy and adulthood.

Props include wrist watches (though frequently the resident's can't read time); engagement rings (highly valued by female residents); official identification cards from the Division of Motor Vehicles; radios; stereo equipment; televisions; purses; and wallets to name a few. When these possessions are acquired and displayed they aid the resident in hiding his or her retarded identity from self and others. This is the process of propping. In this study, the acquisition of a citizens band radio license by Kevin illustrates a unique manifestation of this process.

I got me a C.B. radio license. This is really far out. (He shows me the certificate.) If I can get my drivers' manual done I'm gonna get me a truck and talk on my C.B. That will really be alright (excerpt from field notes).

In this situation, possession of the certificate of registration acted as an important prop to the resident. Though he could not afford to purchase a C.B. radio, and it was questionable as to whether he would pass a driver's test, he acquired a significant prop which symbolically affirmed adulthood to himself.

This resident's acquisition was a unique example of propping. The use of watches, rings, wallets, purses, and nice clothing were more common examples of this phenomenon. Residents were encouraged and instructed by staff to wear and use these things to enhance their adult status. A staff member explained to a group of residents at a weekly meeting: 
Men use wallets that are made to fit in their pockets. Women usually have wallets shaped a little differently, and I think it would also be a good idea for you women to start carrying purses.... When Lonnie went to the hospital last Fall, I was very proud of her. She had her social security card, her I.D. card, the information she needed in her purse (excerpt from field notes).

Most of the female residents in this situation were not in favor of carrying purses. But whether or not residents personally liked props was not relevant. Their value was determined through their importance in facilitating impression management.

All props have a value. They are either positive or negativethey are never neutral. Props which have a negative value can be usefully conceptualized as counter-props as they have the negative effect of enhancing the undesirable visibility of the resident, and countering the impression of normalcy.

Three common examples of counter-props are children's lunch pails, stuffed animals, and clothing which is stereotypically identified as retarded. All three possessions are defined as nonnormalizing by the ideology of normalization and group home staff. Counter-props are defined as having the effect of making residents highly visible to the community in an undesirable fashion. They hinder the process of transforming retardation from a status of visibility to invisibility and serve to reaffirm the mentally retarded identity.

The resident's ability to create the impression of being normal is what makes him or her invisible to the community. Yet as a public, we don't really notice the props, only the surface impression they create. Props on the surface are clearly utilitarian to the resident and the public who are generally uncomfortable interacting with retarded people. However, there is a problematic aspect to teaching various tactics of impression management.

Retarded residents can successfully learn propping strategies which serve to camouflage their retardation and reflect an impression of normalcy, but they remain unable to accurately calculate the behavior of others. Regardless of props and successful behavioral impression management, the residents in this study still did not "glean cues" in interaction with others from which to adopt and calculate behavior that would more consistently help them to blend into society. Propping is a habitual procedure learned by rote. Within a complex society, props are merely a non-calculated surface reflection of social norms. Their usefulness is limited to situations not requiring spontaneous reactions to unanticipated events. Residents become naive and vulnerable in the reality of the community.

A female resident, for example, who had a tubal ligation procedure was planning to be married in the future and desperately wanted to have a child. In discussing her sterilization she explained in a sorrowful tone:

My mom told me that she doesn't want me getting in trouble or spreadin' V.D.R. (V.D.). Do you know what that is? (Counselor) thought is was a good idea and she took me to the hospital-I was scared, but it didn't hurt or nothin'. I was out cold (excerpt from field notes).

Several weeks following this discussion, Molly decided she wanted to have her sterilization operation reversed. She independently telephoned and made an appointment with a doctor and asked the observer to drive her to his office.

The day of the appointment Molly was nervous. The group home operator knew nothing of the plan. Molly had independently made the arrangements, telling only her boyfriend and the observer. On the way to the doctor's office we talked:

Observer: 'Have you talked to your doctor about this, Molly? Does he understand that you want your operation reversed? I didn't think you could reverse a sterilization.'

Molly: 'Yes, Cindy, I talked to him-uh, huh, yes, Cindy, I did' (excerpt from field notes).

The address of the doctor's office led us to a dentist office. "This is a dentist office, Molly," I said, "Are you sure it's the right 
place?" She pointed out that maybe the doctor shared an office with a dentist. Although the observer felt this was a doubtful possibility we walked up to the door and entered the waiting room.

It became immediately apparent to the observer that Molly had made a grave mistake. It was indeed a dentist office! But, not only did this need to be explained to her, It had to be explained to the dentist (who was standing with the receptionist) that Molly didn't need his expertise, but rather a gynecologist. Amazingly, Molly had talked to the dentist on the telephone three times regarding her "painful stitches" which she wanted him to remove. Somehow getting the impression they were stitches in her gums, he had agreed to take her as a patient. Although Molly had learned how to and successfully made her own appointment with a doctor-a mark of independence-she lacked the ability to make important cognitive distinctions which caused her embarrassment and confusion.

An additional situation illustrates how "rote-learned" impression management skills can leave residents vulnerable to lose their money to an unaware public. In this instance, a resident lost over eight dollars to a waitress who assumed he was giving her a generous tip.

I invited Joe to Town-tavern for a beer in a community awareness outing. On the way to the tavern he made it clear, 'I want to pay for your beer-it's on me, Cindy.' We arrive at the tavern, find seats, and Joe orders a pitcher of beer. He is excited to be here. When the waitress brings the beer, Joe hands her a $\$ 10$ bill and says, 'Keep the change.' 'Thanks,' she says, and walks away. I am stunned and not quite sure how to handle the situation. I ask, 'Joe, why did you give the lady so much money?' 'It's okay,' he says smiling, 'I have another one,' as he pulls out a second $\$ 10$ bill. I decided not to approach the waitress, but I feel horrible. After we finish the pitcher, I insist that we leave (excerpt from field notes).

Maintaining the impression of being "normal" while interacting in the unaware public sector got Joe ripped-off in this situation and served to embarrass and confuse Molly. In the reality of the unaware community there are no normalization agents who are responsible for monitoring retarded people's behavior. Consequently, the public frequently creates problems for residents which add to the conflicting messages and encounters which are pervasive in the group home and work settings. In this respect, the community becomes a testing ground as much as a training force for residents.

It is also interesting to speculate as to the advantage that Joe and Molly may have had in their respective situations had they not been successfully passing and propping. Perhaps the waitress would have been less hasty to snatch Joe's change had she realized he was, in fact, mentally disabled and performing a procedure he had learned by rote. And certainly Molly's dentist acquaintance never would have been contacted had the guidance from an advocate been provided. The dilemma becomes: In some situations, successfully maintaining a desirably invisible status may work to the disadvantage of residents in an unaware community. The final contradictory consequence examines the obverse of this dilemma, illustrating a conflict facing residents who fail to blend and are publicly recognized as mentally retarded people.

This final contradictory consequence is also related to the lack of exposure of the general public to mentally retarded people. As the above discussion demonstrates, the consequences of successfully maintaining an impression of normalcy is related to the public person's inability to detect the resident's disability. In the following contradictory consequence the unawareness of the public is related to the visibility of the resident's retardation.

\section{The Sympathetic Agent and Contingency Norms}

Social interaction with any person who possesses a visible stigma creates a certain uneasiness for normal people. The most common tendency is to employ stereotypical categorizations of the stigma as a frame of reference to determine the course of interaction. By virtue of their stereotypical notions about mental retardation, the people who live within the community where retarded persons move about, almost consistently contradict 
the principles of normalization as defined and implemented by group home staff. For the most part they are naive to the movement to deinstitutionalize, normalize, and integrate retarded people, and generally reflect a sympathetic and patronizing attitude in their interaction with residents.

When people on the street confront a person they recognize as being mentally retarded, several responses may follow. A frequent tactic is to treat the retarded person as if he or she is a "non-person," i.e., not present at all and worth only ritual notice. ${ }^{3}$ Another response is to take notice of the intellectual inferiority, feel sympathy for the retarded person because of it, and then make special allowances for him or her as one would with an inexperienced child. This second response is of particular relevance - to this study as it had the effect of reaffirming the retarded identity rather than helping to transform it, which, of course, was the intent of the group home program.

Observation in the public setting suggested attempts on the part of the lay public to reduce the strain of interacting with the residents of legitimizing the visible retarded status through setting up alternative or contingency norms which made special allowances that were not applicable to normal adults. An interaction between a city bus driver and residents provides an example:

We are all standing on the corner-waiting for the bus to pick us up. We are standing around talking-passing time- nobody is doing anything that would draw attention to us. Then the bus drives up. 'Hi, kids,' the bus driver says as we climb in 'Ohhh-hiii,' says Clara, in a loud and boisterous manner. Everyone else in our group also says hi-each in a rather childish manner as we ascend the steps of the bus. The residents and bus driver apparently know each other from before. The bus driver seems to view them as 'big children,' and the residents respond to the expectation of that role (excerpt from field notes).

In the above interaction, the bus driver responded to the residents in a fashion that indicated to them his willingness to accommodate their child-like behavior. His repartee suggested that he held expectations of normative behavior for residents that were contingent upon his stereotypical notions of retarded people. Rather than defining social norms for their behavior in accordance with the values imposed on normal people, he approached their behavior with reference to contingency norms, in accordance with his stereotypical definition of mental retardation.

A second example of this phenomenon occurred at a local coffee house where the observer took two female residents on a community awareness outing:

The different kinds of coffee are listed on a board behind the counter. The situation requires the ability to read the list, make a choice, and then order from the counter. Up to this point, Jerri has successfully reflected an impression of normalcy. She gets nervous as she realizes she must read the menu board. Her face becomes flushed, her mouth drops open, her mannerisms suddenly look stereotypically retarded. She has lost her cover, failed to pass. Although Jerri is capable of reading the list of coffee drinks, if she takes her time, she loses her confidence and stands staring blankly at the waitress behind the counter. The waitress looks at Jerri and the more 'retarded looking' Molly beside her and assesses the situation. She begins to explain as if to a child 'These are the coffees to choose from. Would you like capaccino, expresso... you can have regular coffee, too.' 'Regular coffee,' Jerri says quickly. Jerri is looking down now and doesn't raise her eyes. When the waitress asks Jerri for 50 cents, she gives the waitress a dollar without diverting her downward stare. The waitress gives her change. When Molly moves up to take her turn, the waitress automatically relates to her as if she were a child ordering coffee for her mother. I have not identified myself as being attached to Molly and Jerri which is probably why the waitress is not looking to me for direction in the situation (excerpt from field notes).

In this situation, the waitress recognized that Molly and Jerri were retarded and accommodated what she perceived to be their incompetence. She, as the bus driver, approached their 
behavior with reference to contingency norms that were probably in accordance with her stereotypical expectations for the capabilities of retarded people. Although her behavior was cued by Jerri's reflection of incapability, it nonetheless served to contradict the basic principles of normalization as experienced by Jerri and Molly in the group home.

This situation and the accommodation that the bus driver made for child-like behavior contradicted the expectations of the group home staff whose effort was to teach adult behaviors. Both situations can be likened to "babysitting" which is more clearly apparent in residents' interactions with store and business personnel and their parents. This phenomenon involves the perception of retarded persons as incapable of taking care of their own needs and taking responsibility from residents which they are capable of handling. The response is consistent with the sympathetic conception this society has of mentally retarded people. Consider the following interaction between Joe and a bank teller.

Joe is prepared to deposit a personal check into his savings account. He needs to ask the teller for a deposit slip which he knows how to fill out. His turn in line comes with a teller who has helped him before. Joe says, 'I want to deposit this.' Before he can ask for a deposit slip the teller takes his passbook from his hand and begins to fill out the slip for him. She then instructs him as if speaking to a young child, 'Sign on the back, Joe.' She quickly puts rubber stamps on a 'cash-in' receipt and Joe's passbook. She pushes the passbook in to his hand. She has completely assumed Joe's banking responsibility. Joe and I leave the bank (excerpt from field notes).

Another example of babysitting is illustrated through the actions of Cheri's mother which blatantly contradicted the expectations of group home staff:

Cheri's mother and father are visiting the group home. We (several residents and myself) are all sitting outside and it is beginning to get chilly as the sun goes down. Cheri's mother tells her to get a jacket. Cheri returns outside and her mother takes her jacket from her and helps her put it on. Cheri behaves very child-like around her mother. I learn later in the evening from Lucy (program coordinator) that Cheri's mother continually interferes with the group home program goals by bringing Cheri things, e.g., games and money, and taking Cheri places when she should be learning to use the bus to transport herself. Lucy also says that Cheri's mother shows up at Cheri's activity center much like a parent would visit a child's school (excerpt from field notes).

The above situations experienced by Cheri and Joe, obviously served to contradict the goal to camouflage their undesirably visible retarded status. Babysitting involves publicly recognizing, accepting, and excusing retarded behavior. It directly contradicts the principle of treating retarded persons like responsible adults. As suggested in this study, a consequence is that residents respond in a stereotypical retarded manner to others' child-like perceptions of them which serves only to enhance their visibility as a retarded person.

The motives of such sympathetic agents who babysit residents are innocent. They do not mean to validate the retarded status. In fact, their response is the norm that this society reserves for mentally retarded people. But for the resident, babysitting as well as contingency norms, enlisted by the sympathetic agent, represent another situation where others' judgments, and responses based on them, enhance the role strain experienced as they interact with people who have no understanding of their goal to blend into the community.

\section{CONCLUSION}

The promise of the normalization ideology is so humanistically satisfying and precise in its values and goals, it has provided the direction and cohesion for the current movement to deinstitutionalize and assimilate mentally retarded people into the general community. Indeed, professionals in the field of mental retardation (both academic and non-academic communities) have been so caught up in the fervor and idealism of normalization, 
they have promoted a widespread acceptance of its beliefs without stopping to critically examine the implications of its practical implementation.

The purpose of this research was to begin to ascertain the impact of the implementation of normalization on retarded adults placed in a group home. It was discovered that normalization practice involved a very unidimensional process of isolating specific undesirable and visible behaviors and attempting to camouflage them. This was being attempted through the implementation of an onslaught of continuous behavioral programming that was blinded to the relativity of normative behavior. The primary agents of normalization seemed to have forgotten the fact that although there are many social rules for behavior that can be interpreted in relatively uniform ways in this society, the notion of "normative" behavior is often a fictional prototype rather than a characteristic of the empirical world.

This process of making the person's retardation invisible to society was very complicated for the resident since normalization agents had varying levels of understanding and commitment to the ideology. Furthermore, primary agents responsible for implementing normalization seemed to be unaware of the fact that many rote-learned techniques which allowed residents to blend in the community did not erase their limited ability to make fine cognitive distinctions or manipulate the cultural symbols in this complex intelligent society.

Finally, it is important to note that the conflicts and contradictions of the normalization process which are reported in this research are not meant to serve as an indictment against the movement to community integrate mentally retarded people. The reader is reminded that primary normalization agents are forced to do their job against many constraints such as low budgets, inadequate group home facilities, insufficient staff training, employment settings that are more concerned with production than normalization training, etc. Consequently, principles of normalization must frequently be compromised in practice despite the efforts of the most dedicated staff. Despite the current problems associated with the implementation of normalization, it is most definitely superior to warehousing mentally retarded people in large institutional settings. Hopefully the decade of the 1980s will bring substantial improvement to the normalization movement as it is tested in the empirical world.

\section{FOOTNOTES}

1. Preparation for this manuscript was supported in part by Rehabilitation Research and Training Center grant G008003046 from the National Institute of Handicapped Research, U.S. Department of Education, Washington, D.C. However, those contents do not necessarily represent the policy of that agency, and you should not assume endorsement by the Federal Government.

2. The satellite apartment was an appendage of the group home designed to gradually emancipate the graduate resident. It offered independent living in a neighborhood apartment with continued guidance and advocacy from the group home when needed.

3. Erving Goffman, Asylums (New York: Doubleday and Co., 1961), p. 18, identifies the appearance of this tactic between the stigmatized and normals in social situations.

\section{REFERENCES}

Becker, $\mathrm{H}$.

1963 Outsider. New York: Free Press.

Edgerton, R.B.

1967 The Cloak of Competence. Berkeley: University of California Press.

Glaser, B.G. and Strauss, A.

1967 The Discovery of Grounded Theory: Strategies for Qualitative

Goffman, E. Research. Chicago: Aldine.

1961 Asylums. New York: Doubleday and Company.

Matza, D.

1969 Becoming Deviant. Englewood Cliffs, New Jersey: Prentice-Hall. Scott, R.A.

1969 The Making of Blind Men. New York: Russell Sage Foundation.

Scull, A.T.

1977 Decarceration: Community Treatment and the Deviant-A Radical View. Englewood Cliffs, New Jersey: Prentice-Hall. 
Tinsley, D.J., O'Connor, A.G., and Halpern, A.S.

1973 The Identification of Problem Areas in One Establishment and Maintenance of Community Residential Facilities for the Developmentally Disabled. (Rehabilitation Research and Training Center in Mental Retardation, Center Paper No. 64). Unpublished manuscript, Eugene, Oregon: University of Oregon.

Wolfensberger, $W$.

1972 The Principle of Normalization. Canada: National Institute on Mental Retardation.

\section{BOOK REVIEWS}

Dubois, Paul M. The Hospice Way of Death. New York: Human Sciences Press, 1980,167 pp., $\$ 22.95$ cloth.

In this book, Paul M. Dubois provides a comprehensive overview of the development of the hospice concept and factors involved in its implementation. Hospices, for those unfamiliar with the term, provide palliative care for terminally ill patients who have not responded to aggressive therapy, and to their families. Because hospice care recognizes the needs of those patients whom modern medicine cannot save, DuBois asserts, the medical establishment and the federal government have been obstructively unenthusiastic about their development.

Most of the book is devoted to describing the medieval origins of the hospice and its current components. This includes three lengthy case studies of attempted hospices, two of which have been successfully implemented, and one that failed. There is also a short chapter on demographic and epidemiological changes in death rates since the turn of this century, with implications for the quality of modern, technologically dependent death. A lengthy concluding chapter examines the federal government's response to hospice development. DuBois consistently refers to "the hospice movement," but provides no evidence that there are linkages among the isolated groups working to establish hospices in various locations.

DuBois covers a wide range of material in this book, and it comes across as an odd mix. The reason for this seems to be that he is attempting to reach a broad audience which is poorly targeted. The author states that he wrote the book for "(p)lanners, physicians, and other professionals concerned with health care in the United States, as well as lay people who pay for that care" (p. 11). The result is that the book includes some material which is too basic for part of its potential readership and some that is too involved for another part. Health professionals are well aware of changes in causes of death and death rates over the past century. The inclusion of this material is unnecessary for them. On the other hand, lay people have little use for the exact formula of the 